\title{
Agua y sustentabilidad en la Ciudad de México*
}

\author{
Haydea Izazola**
}

El presente artículo trata sobre la importancia del agua para la sustentabilidad de la Ciudad de México; presenta una breve referencia a sus caracteristicas ecológicas y a las principales transformaciones que sufrió a lo largo del tiempo, modificando su ecosistema natual de origen lacustre para convertirse en una de las ciudades más grandes del planeta. Se analizan los problemas vinculados al abasto de agua, especialmente los relacionados con la creciente dependencia del líquido que proviene de cuencas vecinas; también se examinan los efectos de la explotación del acuifero, las fugas en las redes de suministro, el acceso diferencial del recurso y el tratamiento de aguas servidas. Finalmente, se presentan algunas reflexiones sobre los retos que enfrentará la ciudad para abastecer de agua a la población futura.

\section{Introducción}

Los problemas ambientales de la Ciudad de México comúnmente se asocian a la mala calidad del aire, en especial desde fines de la década de los ochenta, cuando se alcanzaron niveles peligrosos para la salud de la población que motivaron la puesta en marcha de una serie de medidas para mitigar esta situación, con apoyo de importantes fuentes de financiamiento externo.

A pesar de la atención prioritaria otorgada al elemento aire en la Ciudad de México durante los últimos años, muchos otros aspectos vinculados a la crisis ambiental de la ciudad demandan también soluciones urgentes. Entre ellos destaca el manejo del agua, que a lo largo de la historia ha provocado transformaciones radicales en el medio ambiente natural y que en la actualidad impone serios riesgos para la supervivencia de una de las ciudades más pobladas del planeta.

\footnotetext{
* Este artículo está inspirado en el trabajo colectivo presentado por la IV Cohorte de LEAD-México, en la Segunda Sesión Internacional que tuvo lugar en Okinawa, Japón del 16 al 28 de octubre de 1996. Estoy en deuda con todos mis colegas LEAD por las profundas discusiones que sostuvimos sobre este apasionado tema y por la información compartida. La responsabilidad derivada de posibles errores involuntarios es exclusivamente mía. Deseo también agradecer las observaciones de dos dictaminadores anónimos que mejoraron sustancialmente el manuscrito original. Una versión preliminar de este texto será publicada en inglés en Encyclopedia of Life Support Systems, a cargo de la UNESCO.

** Universidad Autónoma Metropolitana-Xochimilco, Departamento de Métodos y Sistemas.
} 
En el presente artículo nos referimos a la importancia del agua para la sustentabilidad de la Giudad de México. Presentamos una breve referencia a sus características ecológicas, a las principales transformaciones que ha sufrido a lo largo del tiempo, que modificaron el ecosistema natural en el que dominaba el agua para sustituirlo por una mancha urbana en la que predomina el asfalto, cada vez más dependiente para su abastecimiento del vital líquido así como para su desalojo de la extracción de agua subterránea y de cuencas externas.

Con ello se pretende destacar que la crisis ambiental por la que actualmente atraviesa la Ciudad de México tiene su origen no sólo en el acelerado crecimiento demográfico que dio lugar a la especulación y a una expansión del suelo urbano sin precedentes, sino principalmente en un insuficiente conocimiento del funcionamiento del ecosistema natural, y del ciclo del agua en particular, lo que pone en riesgo la satisfacción de las necesidades básicas de su población presente y futura.

La solución a la crisis no puede limitarse a la explotación creciente del acuífero y a la importación de agua de cuencas cada vez más lejanas, sino que requiere el concurso de soluciones sociales, económicas, políticas y culturales que promuevan un uso más eficiente y un manejo más racional del recurso. Ello incluye, entre muchas otras acciones, respetar el ciclo hidrológico, abatir el desperdicio por fugas que actualmente se acercan a $40 \%$ de la oferta disponible, aprovechar las aguas pluviales, promover la reutilización de las aguas servidas, evitar el crecimiento de la mancha urbana hacia la periferia de la ciudad, especialmente en zonas de recarga del acuífero, disminuir la desigualdad en el acceso al agua potable entre grupos sociales y promover el pago de precios reales del recurso.

Para garantizar la permanencia de la ciudad, dadas la complejidad y la interdependencia de las soluciones que reclama la actual situación del agua en la Ciudad de México, se requiere un decidido esfuerzo por parte de los diversos sectores de la sociedad, incluidos el gubernamental, el no gubernamental, el sector privado, la academia y la sociedad civil en general.

El medio ambiente natural

La Ciudad de México se localiza a $2 \mathbf{2 4 0}$ metros sobre el nivel del mar en la parte sur de la cuenca de México y se extiende sobre una superficie de aproximadamente 1400 kilómetros cuadrados. 
La cuenca, que originalmente era cerrada o endorreica, ocupa un área de alrededor de $9600 \mathrm{~km}^{2}$ y se encuentra en la parte sur del Eje Volcánico Central, entre los meridianos $98^{\circ} 15^{\prime}$ y $99^{\circ} 30^{\prime}$ y los paralelos $19^{\circ} 00^{\prime}$ y $20^{\circ} 15^{\prime}$. En su longitud mayor mide $110 \mathrm{~km}$ y en la menor $80 \mathrm{~km}$. Las cadenas montañosas que la rodean son de origen volcánico; al norte de la cuenca se localizan las sierras de Tepotzotlán, Tezontlapa y Pachuca, al este los llanos de Apan y la Sierra Nevada, al sur de la cuenca se encuentran las sierras del Chichinautzin y del Ajusco, y al oeste, las sierras de Las Cruces, Monte Alto y Monte Bajo. En el sureste de la cuenca se localizan los picos más altos, el Popocatépetl y el Iztaccíhuatl, con una altitud de 5465 y 5230 metros sobre el nivel del mar, respectivamente.

La cuenca de México, a su vez, se encuentra delimitada por otras cuencas: al norte por las del río Tula y de la Laguna de Meztitlán, al este por la del río Tecolutla, al oeste por la del río Lerma, al sureste por las de los ríos Atoyac y Mixteco, y al sur por la del río Amacuzac.

La cuenca forman parte del Estado de México (48.1\% del área total de la cuenca), de Hidalgo (26.5\%), Tlaxcala (8.8\%), Puebla (1\%) y del Distrito Federal (15.7\%). Este último, sede de los poderes federales, es la entidad federativa a la que se circunscribía la Ciudad de México, pero su crecimiento acelerado, especialmente durante la década de los sesenta, superó los límites administrativos hasta albergar en la actualidad 37 municipios del vecino Estado de México (Conapo, 1997), situación que frecuentemente dificulta la coordinación administrativa necesaria para dar atención a los diversos problemas de la ciudad, y también la generación de información metropolitana.

En el fondo de la cuenca, donde ahora se asienta la Ciudad de México, se encontraba un sistema de lagos que cubría una superficie $1500 \mathrm{~km}^{2}$. Cinco eran los principales lagos: Texcoco, Zumpango, Chalco, Xochimilco, y Xaltocan. El lago de Texcoco, el más bajo del conjunto, recibía toda la escorrentía de la cuenca, antes de evaporarse. Actualmente sólo quedan cerca de $50 \mathrm{~km}^{2}$ de lagos, que incluyen remanentes de Xochimilco, Texcoco, Chalco y Zumpango (Academia de la Investigación Científica et al.,1995:187).

El clima de la Ciudad de México puede considerarse subtropical de altura, templado, semiseco. La temperatura media es de 20 grados centígrados y la temporada de lluvia se concentra entre los meses de mayo y octubre. La precipitación anual es de $700 \mathrm{~mm}$ y su volumen 
total promedio es de aproximadamente $210 \mathrm{~m}^{3} / \mathrm{s}$ (Academia de la Investigación Científica et al., 1995).

De acuerdo con Sanders, Parsons y Stanley (1976) y Niederberger (1987), citados por Ezcurra (1990), existían nueve zonas ambientales dentro de la cuenca: $a$ ) el sistema lacustre; $b$ ) las costas salobres; c) los suelos aluviales y pantanosos; $d$ ) los suelos aluviales someros; $e$ ) los suelos aluviales elevados; $f$ el piedemonte bajo; $g$ ) el piedemonte medio; $h$ ) el piedemonte superior, y $i$ ) el ambiente de las sierras.

Esta diversidad ambiental daba sustento a gran variedad de flora y fauna que, a su vez, proporcionaba suficiente alimentación a los habitantes de la cuenca, aunque, como el mismo Ezcurra señala, el crecimiento de la población provoco, ya en tiempos prehispánicos, la escasez de proteínas animales, que provenían principalmente de la cacería. Esto llevó a las culturas autóctonas a desarrollar técnicas agrícolas (que incluyeron la domesticación de plantas, principalmente el maíz), y a diversificar su dieta, incluyendo un importante componente de vegetales, organismos acuáticos y aves.

No obstante, de acuerdo con Ezcurra, desde tiempos remotos la población de la cuenca recurrió a las importaciones de diversos productos para su sustento. Con base en los estudios de López Rosado (1988) menciona que "en el auge del imperio azteca, México Tenochtitlán importaba de fuera de la cuenca 7000 toneladas de maíz al año, 5000 de frijol, 4000 de chía, 4000 de amaranto, 40 toneladas de chile seco y 20 toneladas de semillas de cacao" (1990: 30).

El recurso más abundante, el agua, que dominaba el medio ambiente y del que eran autosuficientes, representó el elemento fundamental de su economía y su cultura.

\section{La población}

Algunos estudiosos del poblamiento de la cuenca de México estiman que la presencia del hombre se remonta hasta hace 25000 años (Serra, 1990). En el año 5000 a.C. ocurrieron los primeros asentamientos humanos pequeños, y los grandes tuvieron lugar alrededor de 1700 años a.C; se calcula que en el año 100 a.C. la población total ascendía a 15000 habitantes, agrupados en diversos poblados (CNA, 1994). En el año 100 de nuestra era Teotihuacán, localizado al noreste del lago de Texcoco, albergaba a 30000 habitantes, población que 
llego a más de 100000 en el año 650 y que para el 750 disminuyó a tan sólo 10000 (Serra, 1990; Ezcurra, 1990: 33). ${ }^{1}$

Diversas comunidades se fueron asentando en la cuenca y en las márgenes de los lagos. En 1325 los aztecas llegaron a la isleta de Tenochtitlán sobre la cual fundaron su centro religioso, político y económico.

Lograron adaptarse al medio lacustre valiéndose de la construcción de obras hidráulicas que incluyeron acueductos, diques, islotes, canales y el sistema agrícola de chinampas, uno de los más productivos que se hayan desarrollado. Las chinampas son extensiones de terreno formadas por una sucesión de campos elevados dentro de una red de canales dragados sobre el lecho del lago. "El sistema chinampero reciclaba de una manera muy eficiente los nutrientes a través de la cosecha de productos acuáticos de los canales" (Ezcurra,1990: 9-10). Con fines agrícolas también se utilizaron las pendientes de las montañas que rodeaban el valle, donde construyeron terrazas, algunas con sistemas de riego y otras que aprovechaban el agua de los escurrimientos naturales.

La descripción de la gran Tenochtitlán, por parte de los cronistas españoles y otros estudiosos de la historia mexicana, muestra la gran envergadura de las obras hidráulicas que dieron lugar a una de las ciudades más grandes del mundo en el siglo XVI, ya que a fines del siglo XV ocupaba una superfice de $13.5 \mathrm{~km}^{2}$ y contaba con una población estimada en 300000 habitantes en la zona central, y más de un millón si se incluyen los pueblos vecinos de la cuenca ( $i b i d$.$) "comple-$ tamente autosuficientes" respecto al agua (Ezcurra y Mazari-Hiriart, 1996)..$^{2}$

Tras la conquista en 1521, la población comenzó a descender radicalmente para sumar un siglo más tarde sólo $10 \%$ de la alcanzada antes del suceso: menos de 100000 personas para toda la cuenca, y menos de 30000 en lo que fuera la gran Tenochtitlán (Ezcurra, 1990). Este despoblamiento fue consecuencia de las guerras, de la esclavitud, y de la llegada de nuevas enfermedades contra las cuales estaba indefensa la población indígena (Arnold, 2000). Además, el colapso

\footnotetext{
${ }^{1} \mathrm{El} \mathrm{mismo} \mathrm{autor} \mathrm{refiere} \mathrm{que} \mathrm{este} \mathrm{colapso} \mathrm{demográfico} \mathrm{pudo} \mathrm{deberse} \mathrm{al} \mathrm{deterioro}$ ecológico de la región, como consecuencia de la sobreexplotación de los recursos naturales.

${ }^{2}$ García Calderón y De la Lanza (1995:33) hacen referencia a estudios que estiman la población total del altiplano en $\mathbf{2 0}$ millones en el siglo XVI.
} 
religioso, político, económico y cultural que conllevó la conquista desempeño un papel de suma importancia, al igual que la destrucción de la infraestructura urbana y el deterioro ambiental inducido por nuevas formas de apropiación de los recursos naturales, asî como por la introducción de nuevas especies ajenas al medio ambiente natural.

No fue sino hasta principios del siglo Xx (cuatrocientos años después) cuando la población de la ciudad alcanzo de nuevo el tamaño que tenía antes del contacto con los europeos. Después de la revolución de 1910, que concluyó en 1921, retomó su dinamismo y a partir de la década de los cuarenta, en que se inicia el proceso de industrialización por sustitución de importaciones, alcanza las tasas de crecimiento demográfico más elevadas de la historia para convertirse, como hace quinientos años, en una de las más grandes ciudades del mundo.

Lamentablemente la armonía aparente que alcanzó la sociedad azteca con su medio ambiente lacustre se perdió para siempre, en un proceso que desecó los lagos e hizo que la creciente población dependiera del agua proveniente del acuífero y de otras cuencas. Este proceso, que finalmente parece haber logrado su objetivo de combatir el agua, duró casi cinco siglos, mientras que los aztecas en menos de dos siglos alcanzaron a comprender el funcionamiento del ecosistema y lograron una adaptación que permitió el florecimiento de su cultura.

En la actualidad se estima que la población de la ciudad suma cerca de 18 millones (INEGI, 2000a) y está asentada en una superficie de alrededor de $1400 \mathrm{~km}^{2}$, lo que significa que aproximadamente $18.5 \%$ de la población total del país, algo superior a 97 millones de habitantes, se encuentra concentrada en un área inferior a $1 \%$ del territorio nacional, cuya superficie es de casi 2 millones de kilómetros cuadrados.

Este impresionante crecimiento demográfico de la ciudad en el presente siglo se debió a múltiples causas. En primer lugar, la concentración de las actividades económicas en la capital del país atrajo flujos importantes de población, principalmente de origen rural, que se incorporaron a la naciente y pujante actividad industrial atraídos por los mejores salarios, y por los servicios urbanos de la ciudad en franca expansión. En efecto, los servicios educativos, médicos y de salubridad que se fueron proporcionando a cada vez mayor número de habitantes, junto con un acceso a alimentos de mejor calidad, contribuyeron a disminuir la incidencia de enfermedades de origen infec- 
cioso que representaban hasta pocos años antes las principales causas de muerte en el país, disminuyendo así las elevadas tasas de mortalidad, principalmente la infantil. ${ }^{3}$ Ambos fenómenos: elevada inmigración y disminución de la mortalidad, junto con una elevada fecundidad, dieron lugar a una de las más altas tasas de crecimiento demográfico que se hayan registrado en la historia de la población.

Esta situación de auge demográfico, a pesar de su impacto en los números totales de habitantes, cambió en relativamente poco tiempo, pues en los últimos años descendió la tasa de crecimiento, al pasar de más de $5 \%$ promedio anual entre 1950 y 1970 , a alrededor de $1.75 \%$ en la década de los noventa. ${ }^{4}$

Ello ha sido resultado, por un lado, de una menor fecundidad, debido a que las mujeres de la ciudad cuentan en general con mayor escolaridad y participan en el mercado laboral con mayor intensidad que el resto de las mexicanas, elementos ambos que contribuyen a una mayor prevalencia en el uso de anticonceptivos. ${ }^{5}$ Por otro lado, la ciudad ha recibido una menor inmigración proveniente del resto del país. A partir de la década de los ochenta se registra una inversión en los flujos migratorios internos, que antes se orientaban en su gran mayoría a la Ciudad de México, y ahora se dirigen principalmente hacia las ciudades medias del norte y centro del país (Conapo, 1997). La menor atracción de población, en especial en la década de los ochenta, respondió al descenso del dinamismo económico, a la desconcentración de la actividad económica, ${ }^{6}$ y a los problemas ambientales, que empezaron a expulsar a los pobladores (Izazola y Marquette, 1999).

En cuanto a los flujos migratorios, la inmigración pasó de 825000 personas en el quinquenio $1965-1970$ a casi un millón en el periodo 1975-1980, y disminuyó a 559000 entre 1985 y 1990. Por su parte, los emigrantes de la ciudad para los mismos lustros, pasaron de 381000 a 697000 y a un millón, respectivamente. El saldo neto migratorio fue positivo en 444000 entre 1965 y 1970 y en 301000 entre 1975 y 1980 ,

\footnotetext{
${ }^{3}$ Esta tendencia hacia una menor mortalidad continuó en las últimas décadas. La esperanza de vida al nacimiento pasó en la Ciudad de México de 68.6 años entre 1980 y 1985, a 73.2 entre 1990 y 1995 (Conapo, 1997).

${ }^{4}$ De acuerdo con los datos preliminares del Censo de Población de 2000.

${ }^{5}$ La tasa global de fecundidad pasó de 5.4 hijos por mujer entre 1970 y 1975 a 2.5 en el periodo $1990-1995$.

${ }^{6}$ En 1975 se concentraba en la Ciudad de México 45\% del empleo industrial del país. En 1994 solamente $24 \%$ del total nacional se generaba en esta ciudad.
} 
mientras que para 1985-1990 fue negativo en 440 000. Es decir, por primera vez en la historia reciente, la ciudad expulsó más personas de las que recibió (Conapo, 1997).

De acuerdo con las proyecciones oficiales de población del Consejo Nacional de Población, se estima que la Zona Metropolitana de la Ciudad de México alcanzará un total de 20 millones de habitantes hasta el 2010, año en que la tasa de crecimiento que se proyecta llegará a $1 \%$. A diferencia de las proyecciones previas, que estimaban que los 20 millones se alcanzarían en el año de 1995, y con ello la de México se convertiría en la urbe más grande del planeta, la menor fecundidad, pero sobre todo la disminución de la inmigración, ocasionaron que las tasas de crecimiento demográfico declinaran en los últimos años (idem).

\section{CUADRO 1}

Población de la Zona Metropolitana de la Ciudad de México, $1521-2010$

\begin{tabular}{lr}
\hline Año & Habitantes \\
\hline & \\
1521 & 300000 \\
1842 & 101000 \\
1900 & 138000 \\
1910 & 347721 \\
1921 & 471066 \\
1930 & 615367 \\
1940 & 1029068 \\
1950 & 1644921 \\
1960 & 2982199 \\
1970 & 5155327 \\
1980 & 8656851 \\
1990 & 13734654 \\
1995 & 15047685 \\
2000 & 16898316 \\
2010 & 17919158 \\
\end{tabular}

* Proyecciones de Conapo (1997).

Fuentes: INEGI (2000a), XIL Censo general de población y vivienda 2000. Resultados preliminares, Aguascalientes, INEgr; Partida, Virgilio (1994), "La Ciudad de México. Nuevo derrotero en su ritmo de crecimiento", Demos. Carta Demográfica sobre México, 1994, núm. 7, México, UNAM, pp. 13-14; Conapo (1997), Escenarios demográficos y urbanos de la Zona Metropolitana de la Ciudad de México, 1990-2010. Síntesis, México, Consejo Nacional de Población. 


\section{Expansión territorial de la ciudad}

El crecimiento de la población, desde los orígenes de su asentamiento en la cuenca de México, hizo necesaria una cada vez mayor ocupación del espacio, que originalmente estuvo cubierto por agua. Mediante la construcción de islotes con plantas acuáticas y lodo se inició la conquista de los lagos, ganándoles terreno para dar cabida a una sociedad floreciente. La ciudad que encontraron los españoles en 1519 funcionaba gracias a importantes obras de infraestructura hidráulica. En ella predominaban las calles elevadas rodeadas por las aguas del lago que regulaban su nivel, previniendo las inundaciones y la consecuente combinación de aguas dulces y saladas entre los diversos lagos que formaban el ecosistema. Para proporcionar suficiente agua potable a la creciente población, se habían construido dos acueductos de barro que comunicaban los manantiales de Chapultepec, al poniente y de Churubusco al oriente.

Tras la conquista española, el aprovechamiento de los recursos naturales fue transformado y la expansión territorial adquirió nuevas modalidades, que al igual que en el periodo prehispánico, procuraban ganarle terreno a los lagos, aunque de una manera más radical, secándolos por completo. Este proceso, que abarcó varios siglos, fue un factor determinante del crecimiento de la ciudad.

El crecimiento de la población de la Ciudad de México, especialmente en el siglo $\mathrm{XX}$, ha ido acompanado por un proceso de expansión territorial que ha implicado el aprovechamiento del lecho de los lagos desecados para uso urbano, y que se ha extendido, con impactos irreversibles, sobre las montañas que los circundaban y la zona de transición. Estas zonas, dada su alta permeabilidad, filtran no sólo el agua de los escurrimientos, sino también los contaminantes domésticos e industriales, lo que pone en serio riesgo la calidad del agua subterránea (Academia de la Investigación Científica et al., 1995). La ocupación urbana de las zonas de transición y recarga ha sido una práctica común durante las últimas décadas y ha propiciado la construcción de fosas sépticas en las edificaciones regulares, mientras que los asentamientos irregulares, en los que se ha basado principalmente la expansión urbana durante los últimos años, carecen casi en su totalidad de servicio de alcantarillado. Otra práctica común en el presente siglo ha sido el entubamiento de los ríos, así como la combinación de aguas pluviales y fluviales con aguas servidas, para su posterior canalización en los sistemas urbanos de drenaje. 
Cabe mencionar que más de una tercera parte de la zona metropolitana se encuentra construida sobre el área lacustre, y las vivien das que disponen su drenaje en fosas sépticas se localizan en las zonas estratégicas para la recarga del acuífero. De acuerdo con datos del Censo de Población y Vivienda de $1990,17.6 \%$ de las viviendas de la Zona Metropolitana de la Ciudad de México, carecía de drenaje conectado a la calle (Conapo, 1997). ${ }^{7}$

La expansión de la ciudad ha invadido incluso los límites políticoadministrativos. En especial desde fines de la década de los cincuenta, la ciudad se ha extendido no sólo sobre el territorio del Distrito Fe deral, sino que ha abarcado una amplia zona del territorio del Estado de México, situación que dificulta la adecuada administración de los recursos y la generación de información de la zona metropolitana.

En la actualidad la Ciudad de México ocupa una extensión casi cien veces superior a la que alcanzaba en el momento del contacto con los europeos. La evolución del área urbana se muestra en el cuadro 2.

CUADRO 2

Área urbana de la Ciudad de México, 1521-1995

\begin{tabular}{cc}
\hline Año & Kilómetros cuadrados \\
1521 & 13.5 \\
1920 & 46.0 \\
1940 & 117.5 \\
1950 & 260.6 \\
1960 & 416.9 \\
1970 & 722.5 \\
1980 & 891.1 \\
1990 & 1295.5 \\
1995 & 1370.0 \\
\hline
\end{tabular}

Fuente: Conapo (1997), Escenarios demográficos y urbanos de la Zona Metropolitana de la Ciudad de México, 1990-2010. Sintesis, México, Consejo Nacional de Población.

\footnotetext{
${ }^{7}$ Cuando se preparó el presente documento no se disponía aún de la información correspondiente al censo del año 2000 para la zona metropolitana. Sin embargo, los recientemente publicados Tabulados de la muestra censal del XIL Censo general de población y vivienda 2000 , aplicada a $10 \%$ de los hogares del país, muestran que $93 \%$ de las viviendas del Distrito Federal y $76 \%$ de las del Estado de México contaban con drenaje conectado a la red pública.
} 


\section{La transformación del ecosistema}

Para albergar a la creciente población de la Ciudad de México, a lo largo de su historia se ha llevado a cabo una serie de obras de infraestructura que desde tiempos remotos han estado vinculadas al sistema hidráulico de la cuenca. Destacan los esfuerzos por ganar terreno a los lagos mediante la construcción de islotes, que fue la manera en que las sociedades prehispánicas se lograron asentar en el valle, mientras que, tras el contacto con los europeos, se hizo por medio de la apertura de la cuenca y la posterior desecación de los lagos. La transformación del ecosistema se encuentra, en consecuencia, regida por una contradicción curiosa: por un lado, cómo deshacerse del agua natural de la cuenca, que impone límites naturales al crecimiento de la ciudad, y por el otro, cómo abastecer de agua suficiente a la creciente población.

\section{La época prehispánica}

Los aztecas llegaron a manejar con gran maestría el recurso del agua por medio de la construcción de canales, acueductos, presas, acequias, alcantarillas, diques, albarradones y terrazas, que prevenian las constantes inundaciones a la vez que aseguraban el abasto de agua de manantial a la población y el riego con fines agrícolas, ya que el agua de los lagos no era segura para el consumo humano.

A medida que crecía la población, los manantiales locales resultaron insuficientes, de ahí que se construyera alrededor de 1416 el primer acueducto de barro que desde Chapultepec, al poniente de la ciudad, conducía el agua hasta el Templo Mayor, en lo que actualmente es el Zócalo de la ciudad. El acueducto fue destruido por una gran inundación en 1449 y reconstruido por mandato del emperador $\mathrm{Ne}$ zahualcóyotl con materiales más resistentes, por lo que continuaba dando servicio años después de la conquista española (Chávez, 1994).

En 1499, ante el continuo aumento demográfico, fue necesario complementar el abasto de agua y se construyeron nuevas obras para conducirla desde los manantiales de Coyoacán, a pesar de la oposición de la población lugareña. $\mathrm{Al}$ año siguiente una nueva inundación provocada por las lluvias que se prolongaron más de cuarenta días ocasionó su destrucción. Algunos autores mencionan que el emperador azteca ordenó destruir el acueducto, pues consideró que la resistencia a 
su construcción y la posterior inundación eran señales de mal agüero que impedían seguir explotando los manantiales de Coyoacán (idem).

Entre las principales obras que se desarrollaron para extender el espacio habitable, se encuentran las desarrolladas para prolongar el islote original en el que decidieron asentarse los aztecas. Dada la escasez de tierra firme en el sistema de lagos descrito, se construyeron chinampas, que consistían en la acumulación de mantos de plantas acuáticas y lodo extraído del fondo de lago, que se mantenían firmes con estacas de sauce. Inicialmente se utilizaron para construir viviendas y después se destinaron a la agricultura, representando uno de los sistemas más productivos jamás logrados (Ezcurra, 1990). Se calcula que a principios del siglo XVI había 100000 chinampas con tres a diez ocupantes en cada una (DGCOH, 2000a), que daban sustento a una parte importante de la población local. Las localizadas en Xochimilco producían lo suficiente para alimentar a 100000 personas (García Calderón y De la Lanza, 1995).

Por otro lado, y a efecto de prevenir las inundaciones y la mezcla de las aguas salobres del lago de Texcoco con las dulces del resto de los lagos, los aztecas idearon un sistema para controlar el crecimiento de las aguas que consistía en construir diques, mismos que servían de calzadas para comunicar a los islotes del valle. A la llegada de los españoles se contaba con ocho diques cuya longitud iba de 2.5 a 16 kilometros.

Entre este tipo de obras destaca el albarradón ${ }^{8}$ de Nezahualcóyod construido en 1450 , cuya longitud de $16 \mathrm{~km}$ regulaba los flujos entre los lagos; recordemos que por tratarse de una cuenca cerrada, la evaporación del agua con minerales provenientes del escurrimiento de las montañas que rodean el valle se concentraba en el lago más bajo, Texcoco. Los aztecas supieron aprovechar esta situación y explotaron las salinas, logrando disponer de este bien a pesar de hallarse lejos del mar.

El tráfico lacustre, principalmente de mercancías, fue muy importante en el México prehispánico. Se estima que existían más de 200000 canoas, cuatro grandes puertos y múltiples embarcaderos (Chávez, 1994). Todavía a principios del siglo xx era común transportarse por los canales y lagos aún existentes, principalmente en barcos de vapor que navegaban entre Chalco y Xochimilco.

Los esfuerzos para convivir con el agua de manera armónica, sin embargo, fueron derrotados junto con la población indígena tras el

${ }^{8}$ Se trata de un dique construido para separar el agua dulce de la salada y mitigar las inundaciones que afectaban constantemente a la ciudad (Gamboa de Buen, 1994: 20). 
contacto con los europeos. Estos veían en el recurso agua, más que un potencial de crecimiento, un obstáculo para la reproducción de su cultura, en la que la tracción animal, el arado y el cultivo del trigo desempeñaban un papel fundamental.

\section{Las inundaciones y el combate contra el agua}

Como resultado de la destrucción de las obras hidráulicas indígenas, incluido el albarradón de Nezahualcóyotl, así como por el inadecuado manejo del recurso ocasionado principalmente por el desconocimiento de su funcionamiento, y el azolve en el fondo del lago provocado por la deforestación de las zonas montañosas, sobrevinieron a partir de 1555 varias inundaciones de grandes dimensiones que propiciaron la construcción de una serie de proyectos hidráulicos provenientes de ecosistemas distintos, como diques y represas, así como la reconstrucción del albarradón de Nezahualcóyod a mediados del siglo XVI.

No obstante las inundaciones persistían y en 1604 la ciudad quedó anegada durante más de un año. Nuevas obras se emprendían para controlar las aguas, y nuevas inundaciones aquejaban la ciudad, hasta que en 1607 se decidió abrir la cuenca de México (DGCOH, 2000b; Legorreta, 1997).

En este intento destaca la apertura de la cuenca hacia el Golfo de México (a $350 \mathrm{~km}$ de distancia) abriendo un túnel hacia los ríos Tula, Moctezuma y Pánuco a principios del siglo XVII, con la intención de drenar las aguas del valle y sus lagos. Conocido como el canal de Huehuetoca, el túnel inicialmente abarcó $7 \mathrm{~km}$ de longitud y $50 \mathrm{~m}$ de profundidad; posteriormente se le unió el Tajo de Nochistongo, que desviaba las aguas del río Cuautitlán, el principal afluente del lago de Zumpango (DGCOH, 2000b; Legorreta, 1997; Guerrero, 1998).

Sin embargo estas majestuosas obras no lograron superar la vulnerabilidad de la ciudad, y en 1629 sobrevino la peor inundación de la historia, con una duración de cinco años, que causó la muerte de más de 30000 indígenas, $y$ "de las 20000 familias de españoles no quedaban más de 400 en la ciudad inundada. Las otras habían huido hacia las ciudades alejadas de la catástrofe, sobre todo a Puebla" (Musset, 1996: 156). ${ }^{9}$

${ }^{9}$ García Calderón y De la Lanza (1995) hacen referencia a una gran inundación en 1623, que duró tres años y que llevó a considerar la posibilidad de cambiar la capital del país a un sitio más seguro. 
Los retos que imponía esta obra provocaron que no fuera sino hasta 1767 que se lograran evacuar las aguas del río Cuautitlán. No obstante, las inundaciones se siguieron presentando a lo largo del periodo colonial. A finales del siglo xvur (1794) se abre de nuevo la cuenca, ahora por medio del Canal de Guadalupe, que sacaba las aguas del lago Xaltocan (Legorreta, 1997).

En 1867, durante el imperio de Maximiliano de Habsburgo, se inician las obras del Gran Canal del Desagüe, con una longitud de $47 \mathrm{~km}$ y $100 \mathrm{~m}$ de profundidad, desde el lago de Texcoco, el más bajo de la cuenca y sobre el cual se asentaba la ciudad original. Se le conoce como el primer túnel de Tequixquiac, y no fue concluido sino hasta 1895 e inaugurado por Porfirio Díaz en 1900. No obstante, el crecimiento de la mancha urbana y de su población hicieron insuficiente esta obra, de ahí que un nuevo túnel, junto al anterior, fuera construido entre 1937 y 1942, perforando por tercera vez la cuenca. Este túnel se conoce como el segundo túnel de Tequixquiac (idem).

A pesar de esta gran obra, la ciudad siguió anegándose en temporada de lluvias, y a principios de la década de los cincuenta, la ciudad reclamaba su origen lacustre. En 1951 el centro de la ciudad se inundó durante tres semanas y el agua alcanzó dos metros de altura (idem).

Ante la insuficiencia del Gran Canal del Desagüe para controlar las inundaciones del valle, en 1975 se inició la operación del drenaje profundo, que ha contribuido a evitar inundaciones pero ha reproducido la lucha contra el agua que guía el desarrollo urbano desde la época colonial. A 240 metros de profundidad canaliza el agua a través de $164 \mathrm{~km}$ de túneles de hasta 6.5 metros de diámetro, con una capacidad de conducción de hasta $220 \mathrm{~m}^{3} / \mathrm{s}$. En la estación seca, el flujo total es de aproximadamente de $44 \mathrm{~m}^{3} / \mathrm{s}$ (GDF, 2000a).

En conjunto, la ciudad dispone de una estructura para desalojar aguas residuales y escurrimientos naturales consistente en $10237 \mathrm{~km}$ de tuberias en redes secundarias y $2056 \mathrm{~km}$ en redes primarias, 120 colectores marginales, 176 plantas de bombeo, canales a cielo abierto, ríos entubados, presas de almacenamiento y lagunas de regulación. El drenaje desemboca en la parte alta de la cuenca del río Pánuco y posteriormente en el Golfo de México (idem).

En septiembre de 1998 se precipitaron las más intensas lluvias desde hace 111 años y fue desalojado un caudal promedio de $315 \mathrm{~m}^{3} / \mathrm{s}$ (idem), mientras que el abasto promedio actual es de $63 \mathrm{~m}^{3} / \mathrm{s}$, correspondiente a $20 \%$ del caudal desalojado en esa fecha. 
Por casi cinco siglos el hombre ha luchado en contra del agua en la Ciudad de México, invirtiendo cuantiosos recursos para secar los lagos que originalmente le daban su sustento. Tantos intentos y recursos destinados a este fin lograron que la antes autosuficiente Ciudad de México se convirtiera, a partir de la década de los cincuenta, en importadora de agua proveniente de otras cuencas, además de que se ha sobreexplotado el agua del subsuelo con graves efectos para el medio ambiente natural y construido. El agua, un recurso antes abundante, se ha convertido en escaso y caro, lo que pone en riesgo la supervivencia de la ciudad y sus habitantes.

\begin{abstract}
Abasto de agua potable
El abastecimiento de agua potable siempre fue un problema para los pobladores de la ciudad. Se ha mencionado que ya a principios del siglo XV se dependía de manantiales alejados de la Gran Tenochtitlán: Chapultepec y Coyoacán. A principios del siglo XVII comenzó la dependencia de los manantiales de Santa Fe, al poniente de la ciudad, cuya agua era transportada por medio de un acueducto de $6 \mathrm{~km}$ de longitud. Un siglo después éste sufrió severos daños y se diversificaron las fuentes de abastecimiento, construyéndose nuevos acueductos provenientes de Tlalpan y San Ángel, al sur de la ciudad, y de Guadalupe al norte.
\end{abstract}

Ante la creciente escasez de agua, también se inició la explotación del agua subterránea con la construcción de pozos artesianos a mediados del siglo XIX. Hacia 1878 el agua potable resultó de nuevo insuficiente para la población y se recurrió a los manantiales del Desierto de los Leones también al poniente de la ciudad, aún más alejados que los de Santa Fe. Esta dependencia del recurso se fue extendiendo hacia sitios más remotos, e incluso se llegó a captar agua proveniente de los llanos de Salazar, iniciándose las importaciones desde otra cuenca, aunque de poca magnitud (Legorreta, 1997).

En 1900 el caudal disponible en la ciudad ascendía a $480 \mathrm{l} / \mathrm{s}$ $\left(0.48 \mathrm{~m}^{3} / \mathrm{s}\right)$ (DGCOH, 2000c), que representaba un consumo promedio por habitante al día de tan sólo 122 litros, considerando que la población en ese año sumaba 340000 habitantes, ligeramente superior a la registrada hacia finales de la época prehispánica.

Al año siguiente el abasto de agua pasó a 570 l/s y en 1902 ascendía a $862 \mathrm{l} / \mathrm{s}$, proviniendo $42 \%$ de los 1376 pozos que existían en la 
ciudad. En 1903 la oferta de agua creció a $938 \mathrm{l} / \mathrm{s}$ y en 1905 a 963 , de los cuales $40 \%$ se extraía de pozos y el resto de manantiales y aguas superficiales (idem).

Ante esta especial modalidad del manejo del recurso, el abasto de agua siempre ha quedado a la zaga frente a la demanda de la población y de las actividades económicas de la ciudad. En tal virtud, un nuevo acueducto fue construido entre 1905 y 1908 para conducir el agua procedente de los manantiales de La Noria en Xochimilco, que se concentraba en los tanques del Molino del Rey, a $26 \mathrm{~km}$ de distancia. Esta obra sustituyó el abasto de los manantiales de Chapultepec y del Desierto de los Leones a partir de 1912 (Legorreta, 1997).

Hacia 1927, algunos años después de la Revolución, la ciudad recibía un caudal de $2.5 \mathrm{~m}^{3} / \mathrm{s}$ para abastecer a una población de un millón de habitantes, lo que representaba un promedio de 216 litros por habitante al día (DGCOH, 2000c).

Una década después, la ciudad enfrentaba de nuevo escasez de agua y se procedió a la perforación de 18 pozos profundos, de entre 100 y $200 \mathrm{~m}$. Esta solución, sin embargo, generó un efecto no deseado: el hundimiento del terreno, provocado por la sobreexplotación de las aguas subterráneas (Legorreta, 1997).

Por ello se decidió recurrir a la importación del líquido, en magnitudes importantes, de cuencas externas. Se eligió el acuífero del río Lerma, en el Valle de Toluca, pues por gravedad podría abastecer de agua a toda la ciudad. Se estimó un caudal inicial de $6 \mathrm{~m}^{3} / \mathrm{s}$, para llegar a un total de $14 \mathrm{~m}^{3} / \mathrm{s}$ y proporcionar agua a una población de 2.8 millones de habitantes (que alcanzó la ciudad en 1950). La dotación diaria sería de 430 litros por habitante (DGCOH, 2000c), pero en el transcurso de la realización del proyecto se modificó a 400 litros diarios por habitante para una población de 4 millones que tenía la ciudad en la segunda mitad de los cincuenta.

En el año de 1941 se iniciaron las obras para conducir el agua desde los pozos de la cuenca del Lerma a través de un acueducto de $15 \mathrm{~km}$ sobre la sierra de Las Cruces, a más de 3000 metros sobre el nivel del mar. Sin embargo la complejidad de las obras retrasó el inicio de su operación, y en 1948 se aumentó de manera importante la perforación de pozos con el consiguiente hundimiento del terreno.

Formalmente las obras del sistema Lerma comenzaron a operar en 1951 y, en efecto, proporcionaron en sus inicios 4 m³. En 1952 la población de la ciudad sumaba alrededor de 3.5 millones de habitantes y la disponibilidad de agua ascendía a $13.1 \mathrm{~m}^{3} / \mathrm{s}$, lo que representaba un 
promedio diario por habitante de 327 litros al día (idem). No obstante, únicamente $50 \%$ de la población contaba con servicio domiciliario.

En la década de los setenta el sistema Lerma llegó a abastecer de $13.7 \mathrm{~m}^{3} / \mathrm{s}$ a la Ciudad de México, lo que provocó efectos adversos a la cuenca, de ahí que se buscaran fuentes alternativas de abastecimiento (GNA y Semarnap, 1997: 11).

Se determinó que la cuenca del río Cutzamala, en el Estado de México, era la más idónea, dada la calidad y cantidad de agua con la que contaba, a pesar de que se localiza a $126 \mathrm{~km}$ de la Ciudad de México y que es necesario bombearla más de $1200 \mathrm{~m}$, dada la diferencia de altitud con la cuenca de México. El sistema Cutzamala empezó a funcionar en 1982 y actualmente proporciona cerca de una cuarta parte del abastecimiento total de agua a la ciudad (CNA, 1999).

\section{Fuentes de abastecimiento del agua}

Si bien a principios del siglo $40 \%$ del abasto de agua provenía de los pozos perforados en el interior del valle de México, y el resto, $60 \%$, tenía su origen en las aguas superficiales, esta situación, como muestra el cuadro 3, ha cambiado de manera radical. En las aguas subterráneas del valle tiene su origen $65 \%$, por medio de 1223 pozos en el propio valle y $9 \%$ en los localizados en la cuenca del Lerma, en tanto solamente $2 \%$ proviene de aguas superficiales (Academia de la Investigación Científica et al., 1995).

De acuerdo con datos de la Comisión Nacional del Agua, la precipitación pluvial media anual asciende a cerca de 7000 millones de $\mathrm{m}^{3}$, y se concentra en cuatro meses. De ese total, $80 \%$ se evapotranspira, $11 \%$ se infiltra en el subsuelo, y $9 \%\left(19 \mathrm{~m}^{3} / \mathrm{s}\right)$ escurre superficialmente. De este último volumen, caracterizado por una elevada contaminación, solamente una pequeña parte $\left(1.4 \mathrm{~m}^{3} / \mathrm{s}\right.$, es decir menos de $\left.10 \%\right)$ se aprovecha, mientras se desaloja el resto por el sistema de drenaje junto con las aguas servidas, para evitar inundaciones (Ramírez, 1990). Como se expuso con anterioridad, se estima que en septiembre de 1998 se desalojaron más de $315 \mathrm{~m}^{3} / \mathrm{s}$ como resultado de una extraordinaria temporada de lluvias que produjo la precipitación más alta en 111 años (GDF, 2000b).

Este manejo del agua en la Ciudad de México, que desaloja el agua de lluvia, ocasiona que se dependa cada vez más de la explotación del acuífero y de la importación de cuencas vecinas para cubrir la necesidades de la población y de sus actividades económicas. Para 
octubre de 1999 se estimaba que el suministro total llegaba a $63 \mathrm{~m}^{3} / \mathrm{s}$, provenientes de las fuentes ${ }^{10}$ señaladas en el cuadro 3 .

\section{CUADRO 3}

Fuentes de suministro de agua en la Ciudad de México.

Distribuciones promedio para octubre de 1999

\begin{tabular}{lcc}
\hline Procedencia & Metros cúbicos por segundo & Porcentaje \\
\hline Valle de México & & \\
$\quad$ Aguas superficiales & 1.4 & 2.2 \\
Aguas subterráneas & 41.1 & 65.1 \\
Subtotal & 42.5 & 67.3 \\
Otras cuencas & & \\
Lerma-subterráneas & 5.8 & 9.2 \\
Cutzamala-superficial & 14.8 & 23.5 \\
Subtotal & 20.6 & 32.7 \\
Total & 63.1 & 100.0 \\
\hline
\end{tabular}

Fuente: Comisión Nacional del Agua, 1999.

Este impresionante caudal (5.5 millones de $\mathrm{m}^{3}$ diarios, o casi 2000 millones de $\mathrm{m}^{3}$ al año se destina principalmente a la población urbana $(67 \%)$; a la industria $17 \%$ y al comercio y los servicios $16 \%$; sin embargo, su aprovechamiento no es del todo eficiente, principalmenic debido a una importante pérdida por fugas, como veremos posteriormente.

Agua subterránea

Frente a la paulatina desecación de los lagos originales, la disminución del agua de manantial y la contaminación de los ríos de la ciudad, fue necesario recurrir a la extracción de agua subterránea a partir de la segunda mitad del siglo XIX.

${ }^{10}$ Este monto se ha mantenido constante desde 1995 y se calcula que los trabajos de la última etapa del Sistema Cutzamala (del río Temascaltepec) "requerirán, desde el momento en que se inicie su ejecución, de más de tres años para aportar nuevos caudales que representarán 2000 litros por segundo para el Distrito Federal y un caudal igual para el Estado de México" (Buenrostro, 2000: 11). 
Conviene mencionar que el acuífero de la Ciudad de México se encuentra al sur de la cuenca de México, y cubre una extensión aproximada de $3448 \mathrm{~km}^{2}$, aunque los estudios que se realizan sobre su capacidad de regeneración, generalmente cubren una porción menor de este total. Una cuarta parte del acuífero está cubierta por capas gruesas de arcilla de muy baja permeabilidad que lo protegen de la contaminación antropogénica, pero las zonas de recarga, especialmente las de transición y de montañas, son más susceptibles a este tipo de contaminación (Academia de la Investigación Científica et al., 1995).

En 1847 se perforó el primer pozo en el centro de la ciudad con una profundidad de 40 metros, y se extrajo agua de excelente calidad. En 1864 ya existían 200 pozos artesianos; en 1877, 483 y en 1888 . 1 100. Estos pozos fueron la causa de los primeros hundimientos en el periodo 1881-1895, los cuales promediaron $5 \mathrm{~cm}$ por año en la zona central de la ciudad (idem).

Antes de 1940, el agua provenía principalmente de los manantiales de Xochimilco, pero entre 1940 y 1944 se inició la explotación intensiva del acuífero con la perforación de 75 pozos profundos de hasta 200 metros. No obstante, el creciente hundimiento de la ciudad provocó que en la década de los cincuenta se decretara la suspensión de la explotación del acuífero, y solamente se permitió realizar perforaciones en el sur del valle, en Xochimilco, Chalco y Zumpango, a una profundidad que ha llegado a 400 metros en áreas cercanas a las zonas de recarga. En 1954 se estimaba que el caudal proveniente de los pozos ascendía a $8 \mathrm{~m}^{3} / \mathrm{s}$, que se ha quintuplicado en la actualidad, al llegar a 41 m³ s (CNA y Semarnap, 1997; Legorreta, 1997; Academia de la Investigación Científica et al., 1995).

Ya en 1990 había 3537 pozos en el valle, de los cuales 1223 (la tercera parte) proporcionaba agua de uso urbano: $42 \mathrm{~m}^{3} / \mathrm{s}$, en tanto que el resto destinaba el recurso a usos industrial, agropecuario, doméstico, etc., con un caudal de $9 \mathrm{~m}^{3} / \mathrm{s}$ en promedio (Academia de la Investigación Científica et al, 1995: 136, cuadro 2.4.2).

La explotación de agua subterránea ha causado preocupación entre la comunidad científica, que ha elaborado múltiples estudios sobre la capacidad de recarga del acuífero, principal fuente de abastecimiento del líquido para la ciudad (entre otros, Herrera, 1989; Herrera et al. 1994; Murillo, 1990, todos citados en Academia de la Investigación Científica et al., 1995).

El volumen de la porción del acuífero que ha sido estudiada con mayor profundidad y del que se estimó una extracción promedio 
para el periodo $1991-1993$ de casi $28 \mathrm{~m}^{3} / \mathrm{s}$ (alrededor de $70 \%$ del total), se calcula en $2149.4 \times 10^{9} \mathrm{~m}^{3}$, que puede representar entre $345 \mathrm{y}$ 213 veces el déficit anual (idem:149). Sin embargo, múltiples razones impiden aprovechar todo su potencial y los estudiosos del tema advierten sobre los inconvenientes de explotarlo más allá de su capacidad de recarga, calculada en $15.6 \mathrm{~m}^{3} / \mathrm{s}$ (idem). Es decir, el déficit o sobreexplotación en la parte referida del acuífero alcanza 56 por ciento.

Por su parte, Mazari-Hiriart y Bellón (1995) hacen referencia a una recarga de $25 \mathrm{~m}^{3} / \mathrm{s}$ y una extracción promedio $\mathrm{de} 45 \mathrm{~m}^{3} / \mathrm{s}$ para todo el acuífero de la ciudad; es decir un déficit de $20 \mathrm{~m}^{3} / \mathrm{s}$, o 40\%. Basados en estudios previos, los autores calculan que la capacidad natural del sistema para proveer agua a la población se alcanzó en 1964, considerando que no se superaba la capacidad de regeneración del recurso.

El Plan Maestro de Agua Potable 1999 se proyectó para la parte del acuífero del valle de México correspondiente al Distrito Federal, la cual se divide en tres subsistemas independientes: Ciudad de México, que cubre toda la zona urbana y coincide con el Distrito Federal, Texcoco y Chalco. El déficit entre extracción y recarga se muestra en el cuadro 4.

CUADRO 4

Déficit entre extracción y recarga. Acúfero del Distrito Federal, 1999

\begin{tabular}{lccc}
\hline Subsistema del acuífero & Extracción $\left(\mathrm{m}^{3} / \mathrm{s}\right)$ & Recarga $\left(\mathrm{m}^{3} / \mathrm{s}\right)$ & Déficit $(\%)$ \\
\hline & & & \\
Ciudad de México & 11.35 & 8.00 & 37 \\
Texcoco & 8.05 & 5.19 & 55 \\
Chalco & 5.67 & 4.54 & 25 \\
Total & 25.07 & 17.73 & 39
\end{tabular}

Fuente: Plan Maestro de Agua Potable, DGCOH, DDF, 1999.

Hundimientos. Entre las consecuencias de la explotación del agua subterránea destacan la declinación de los niveles de agua en el acuífero (nivel piezométrico), el hundimiento del terreno en la Ciudad de México, así como la exposición del acuífero a la contaminación. Ello es debido a la desecación de los lagos y a que la extracción ha sido superior a la recarga del acuífero. 
Los hundimientos han sido registrados desde fines del siglo pasado, y su velocidad ha sido estudiada por distintos investigadores (Mazari y Alberro, 1990; Academia de la Investigación Científica et al., 1995). Se estima que la mayor velocidad de hundimiento se registró en el periodo 1950-1951, cuando alcanzó entre 35 y $46 \mathrm{~cm} /$ año, situación que llevó a decretar la suspensión de la perforación de pozos en 1954 (Mazarí y Alberro, 1990; Academia de la Investigación Científica et al., 1995).

Para el periodo 1987-1991 esta velocidad descendió a $9.2 \mathrm{~cm}$, aunque mostró importantes variaciones en distintas áreas de la ciudad $(10 \mathrm{~cm}$ en el centro, $15 \mathrm{~cm}$ en Xochimilco, 20 a 25 en la zona del Aeropuerto al oriente de la ciudad, $30 \mathrm{~cm}$ en Nezahualcóyotl -la mayor-, y las menores en las zonas no lacustres, como Azcapotzalco, que se hundió entre 2 y $5 \mathrm{~cm}$ ), después de que su mínimo registro fue de $4.5 \mathrm{~cm}$ entre 1973 y 1977, y de 4.6 entre 1977 y 1982 (Legorreta, 1997; Academia de la Investigación Científica et al., 1995). Mazari y Alberro (1990.) estiman que durante los sismos de 1985 "la superficie del suelo sufrió un brusco asentamien to cuyo promedio, por lo menos en los puntos tomados como referencia, es [...]11 cm" (p. 94).

La catedral metropolitana se ha hundido 12.5 metros desde el inicio de su construcción en el siglo Xvi; el principal hundimiento, de 7.5 metros, ocurrio en el siglo Xx. Entre 1950 y 1980 la zona central de la ciudad se hundió 5 metros (Legorreta, 1997; Mazarí y Alberro, 1990). La evolución del hundimiento promedio, calculado con base en la información disponible se presenta en el cuadro 5.

Por lo que se refiere a la declinación de los niveles de agua en el acuífero, algunos estudios encontraron que éstos se abaten en promedio 1 a 1.15 metros al año, aunque con variaciones importantes al interior del mismo (Academia de la Investigación Científica et al., 1995; Mazari, 1997). En el cuadro 6 se presentan las estimaciones para el periodo 1988-1991. 
GUADRO 5

Evolución del hundimiento en la Giudad de México, 1891-1991

\begin{tabular}{lccc}
\hline $\begin{array}{c}\text { Periodo de } \\
\text { nivelación }\end{array}$ & $\begin{array}{c}\text { Hundimiento } \\
(\mathrm{cm})\end{array}$ & $\begin{array}{c}\text { Periodo } \\
(\text { años })\end{array}$ & $\begin{array}{c}\text { Rapidez media } \\
(\mathrm{cm} / \text { año })\end{array}$ \\
\hline & 212 & & \\
$1891-1938$ & 76 & 47 & 4.5 \\
$1938-1948$ & 88 & 10 & 7.6 \\
$1948-1950$ & 46 & 2 & 44 \\
$1950-1951$ & 15 & 1 & 46 \\
$1951-1952$ & 26 & 1 & 15 \\
$1952-1953$ & 68 & 1 & 26 \\
$1953-1957$ & 24 & 2 & 17 \\
$1957-1959$ & 22 & 4 & 12 \\
$1959-1963$ & 21 & 3 & 5.5 \\
$1963-1966$ & 28 & 4 & 7 \\
$1966-1970$ & 17 & 3.4 & 7 \\
$1970-1973$ & 18 & 4 & 5.1 \\
$1973-1977$ & 23 & 5 & 4.5 \\
$1977-1982$ & 25 & 3.4 & 4.6 \\
$1982-1986$ & 46 & 5 & 7.4 \\
$1986-1991$ & & & 9.2
\end{tabular}

Fuente: Reproducido de El agua y la Ciudad de México, Academia de la Investigación Científica et al. (1995: 141).

CUADRO 6

Promedio anual de abatimiento del nivel freático, 1988-1991

\begin{tabular}{lc}
\hline Zona & Promedio anual de abatimiento $(m)$ \\
\hline Ciudad de México & 0.9 \\
Tláhuac-Xochimilco & 1.2 \\
Chalco & 0.9 \\
Guautitlán & 1.5 \\
Tizayuca-Pachuca & 1.0 \\
Texcoco & 0.9 \\
Apan & 0.1
\end{tabular}

Fuente: Reproducido de El agua y la Ciudad de México, Academia de la Investigación Científica et al. (1995: 138). 
La problemática de los hundimientos tiene implicaciones ambientales y económicas, ya que tanto la infraestructura urbana como las capas de arcilla que recubren el valle se encuentran en grave riesgo de sufrir fisuras. En la Ciudad de México se han detectado fracturas en las arcillas, lo que puede propiciar la contaminación del acuífero proveniente de aguas superficiales (Academia de la Investigación Científica et al., 1995; Mazari-Hiriart et al., 2000).

Cabe señalar que el impacto de los hundimientos sobre las obras de drenaje ha sido especialmente notorio. En 1910, el lago de Texcoco, al que fluía parte del drenaje por gravedad, se encontraba 1.90 metros por debajo del centro de la ciudad y en 1970 se encontraba 5.50 metros arriba. En tal virtud, fue necesario bombear el agua con un importante costo energético y en 1975 hubo que poner en marcha el drenaje profundo. Este fue diseñado para desalojar el agua pluvial previniendo el efecto de los hundimientos, por lo que la canaliza a través de varios interceptores a profundidades que llegan hasta 240 metros y es operado por gravedad (GDF, 2000a).

\section{Cuencas externas}

Ya se ha mencionado que el abastecimiento de agua para la Ciudad de México depende cada vez más de cuencas externas, en virtud de la insuficiencia de las aguas superficiales y de los riesgos que implica explotar progresivamente el acuífero.

Desde principios de la década de los cincuenta se inició la importación de agua proveniente del río Lerma, que inicialmente proveyó de $4 \mathrm{~m}^{3}$ s a la ciudad, gracias a una obra que fue monumental en su momento.

En virtud de que este proyecto ocasionó serios problemas ecológicos, sociales, económicos y políticos, a inicios de la década de los setenta, cuando proporcionó $13.7 \mathrm{~m}^{3} / \mathrm{s}$ (CNA y Semarnap, 1997), se iniciaron estudios de otras cuencas cercanas a efecto de complementar el abasto a la ciudad, que seguía demandando cantidades de agua cada vez mayores. Se seleccionó la cuenca del río Cutzamala, ubicada $126 \mathrm{~km}$ al poniente de la urbe.

El sistema Cutzamala se proyectó para operar en varias etapas con la siguiente capacidad:

Primera etapa. Inició su operación en 1982, aportando $4 \mathrm{~m}^{3} / \mathrm{s}$ provenientes de la presa Villa Victoria. 
Segunda etapa. Comenzó a funcionar en 1985 con una capacidad de $6 \mathrm{~m}^{3} / \mathrm{s}$ de la presa de Valle de Bravo

Tercera etapa. Está proyectada para operar a una capacidad de $9 \mathrm{~m}^{3} / \mathrm{s}$; actualmente proporciona cerca de $5 \mathrm{~m}^{3} / \mathrm{s}$ (CNA y Semarnap, 1997; CNA, 1999).

En el presente se obtienen de este sistema en su conjunto cerca de $15 \mathrm{~m}^{3} / \mathrm{s}$, lo que representa casi una cuarta parte del abasto total de la ciudad (CNA, 1999).

La capacidad del sistema Cutzamala, una vez que llegue a su etapa final, proporcionará $19 \mathrm{~m}^{3} / \mathrm{s}(30 \%$ del abasto actual de la ciudad) (CNA y Semarnap, 1997), ${ }^{11}$ aunque en los últimos años la población de Temascaltepec, desde donde se canalizará el agua, se ha opuesto al proyecto de manera radical. Argumenta, y con razón, que la desviación de sus recursos naturales en beneficio de la ciudad más grande del país no sólo tendría efectos adversos en el medio ambiente local, sino en sus actividades económicas, su cultura y su vida cotidiana.

Frente a los conflictos que ha generado la continuación del proyecto Gutzamala, las autoridades que administran el agua en la Ciudad de México se han propuesto optimizar el manejo del líquido mediante la eliminación de fugas, reutilización de las aguas servidas, aumento del precio para disminuir la demanda, y nuevas normas de construcción, como la utilización de inodoros con seis litros de capacidad, en lugar de los de 16 litros que se usaban antes de 1989, entre otras medidas.

Cada metro cúbico de agua obtenido del sistema Cutzamala "requirió de una inversión de 23 millones de dólares, y se calcula que los costos se cuadruplicarían si fuera necesario explotar otras cuencas, como la del río Amacuzac", al sur de la ciudad (Encinas, 1999: 54).

Actualmente se estima que el subsidio que se otorga a los consumidores representa entre $66 \%$ y $90 \%$ del costo real del abastecimiento de agua. Una medida que ayudaría a racionalizar la demanda consistiría precisamente en cobrar precios que reflejen el costo real; sin embargo, ante el cada vez mayor deterioro del poder de compra de la población capitalina, difícilmente se podrá lograr este objetivo en el corto plazo.

\footnotetext{
${ }^{11}$ Algunas estimaciones recientes calculan el potencial del sistema en $24 \mathrm{~m}^{3} / \mathrm{s}$ para su etapa final DGCOH (2000c).
} 


\section{Consumo de agua}

La evolución de la disponibilidad per cápita ha variado en el tiempo. Se estima que en la época prehispánica el consumo era elevado, dadas las costumbres de la época que incluían el baño diario, el frecuente lavado de ropa, así como la limpieza de los bienes inmuebles. No obstante, carecemos de estimaciones precisas acerca del consumo per cápita.

Las cifras disponibles se refieren principalmente al siglo Xx. Por ejemplo, para el año 1900, con base en las cifras de población y de abasto, calculamos un abasto promedio de 122 litros por habitante al día (DGCOH, 2000a).

Para 1927 se dispone de información que indica que el abasto promedio ascendía a 216 litros por habitante al día. En 1937 era de 430 litros por habitante al día. En 1951, con la puesta en operación de sistema Lerma, se proveyó a la población de 340 litros por habitante al día, y en 1952 de 327 . El abasto diario promedio per cápita en 1964 era de 330 litros y en 1975 el agua disponible sumaba $32 \mathrm{~m}^{3} / \mathrm{s}$ para una población estimada en 11 millones de habitantes, lo que arrojaría un abasto per cápita diario promedio de 282 litros, cifra bastante inferior a la registrada en las últimas décadas (DGCOH, 2000c).

Para 1994 se estimaba en 337, para 1997 en 324, y en la actualidad, considerando una población aproximada de 18 millones de habitantes, con un abasto de $63 \mathrm{~m}^{3} / \mathrm{s}$, podemos calcular una disponibilidad promedio de alrededor de 300 litros por habitante al día.

La Organización Mundial de la Salud recomienda un abasto diario de 150 litros por habitante para las ciudades de los países desarrollados: en Tokio, Nueva York y París no se sobrepasan los 200 litros (Population Information Program, 1999; DGCOH, 2000c).

El Banco Mundial establece un mínimo de 50 litros disponibles por habitante al día para evitar problemas de salud (idem).

En la Ciudad de México se estima que una dotación confort, entendida como la cantidad mínima de agua que requiere un ser humano para satisfacer principalmente sus necesidades de alimentación y de higiene es de 196 litros diarios por habitante, aunque tradicionalmente se ha considerado para las estimaciones de la demanda un total de 351 litros por habitante al día (GDF, 2000a). Este diferencial radica en que la segunda cantidad incluye el abasto a los sectores industrial, comercial y municipal. 
En Estados Unidos se usa para fines personales un promedio de 600 litros al día por habitante, mientras que en India este promedio es de tan sólo 50 litros (Population Information Program, 1999).

La diversidad de las cifras puede reflejar los distintos patrones de uso del agua a lo largo del tiempo y la desigual distribución del recurso, pero tal discrepancia también puede estar afectada por una posible inexactitud de los datos, tanto de población como de oferta de agua. Sería encomiable que a principios de siglo el agua fuera mejor aprovechada y que se racionalizara su consumo, o bien, que su distribución desigual entre la población no se reflejara en las cifras promedio.

Esta última dificultad persiste, ya que el agua en la Ciudad de México escasea en temporadas de estiaje, principalmente en las zonas menos privilegiadas económicamente. La expansión de la ciudad sobre diferentes unidades político-administrativas dificulta también la generación de información confiable para la zona metropolitana en su conjunto.

A pesar de que en el censo de 1990 se registró que $90 \%$ de las viviendas tiene acceso a agua potable, en la práctica el abasto no es regular y su distribución es muy desigual. Conviene mencionar que el acceso al agua entubada dentro de las viviendas solamente alcanzó a $64 \%$ de las viviendas de la Zona Metropolitana de la Ciudad de México. Cabe advertir que en 1950 esta proporción era del 43.5 por ciento. ${ }^{12}$

Se calcula que en la actualidad un millón de personas reciben agua por tandeo en el Distrito Federal, pese a que cuentan con red de distribución de agua potable (Buenrostro, 2000).

En zonas pobres de la ciudad, García Lascurain (1995) detectó consumos per cápita promedio de 24 y 19 litros en temporadas de abasto más o menos regular a través de pipas, en Chalco y Ecatepec, respectivamente; sin embargo, estos consumos bajaron hasta un ran-

12 En el momento de preparar este documento aún no se disponía de la información correspondiente al censo del año 2000 para la zona metropolitana. Sin embargo, los recientemente publicados Tabulados de la muestra censal del XIL Censo general de pobla ción y vivienda 2000 , aplicados a $10 \%$ de los hogares del país, muestran que $78 \%$ de los del Distrito Federal y $54 \%$ de los del Estado de México disponían de agua en el interior de la vivienda, por lo que podemos suponer que no hubo un avance significativo en la prestación de este servicio esencial en la década de los noventa. Cabe mencionar que las viviendas que carecían de agua entubada en el Distrito Federal se abastecieron casi totalmente (92\%) por medio de pipas, mientras que en el Estado de México, las dos terceras partes de las viviendas carentes de este servicio $(67 \%)$ lo hicieron por medio de agua de pozo, río, lago, arroyo y otras fuentes (INEGI, 2000b). 
go entre 4 y 14, y 7 litros respectivamente, en temporada de lluvias (paradójicamente), cuando las condiciones de los caminos impedían la llegada de los carros tanque. ${ }^{13}$

Legorreta (1997) estima que en los sectores pobres el consumo es de 28 litros diarios per cápita, mientras que en los sectores medios varía entre 275 y 410 litros, y en los de máximos ingresos el consumo promedio diario es de entre 800 y 1000 litros por habitante.

Si consideramos que casi $40 \%$ de la oferta de agua se pierde en fugas, quedarían únicamente alrededor de $38 \mathrm{~m}^{3} / \mathrm{s}$ disponibles para el consumo humano y las actividades industriales, comerciales, urbanas y de servicios. De este caudal, 33\% se destina a la industria, el comercio y los servicios, por lo que quedarían para uso personal de la población alrededor de $25 \mathrm{~m}^{3} / \mathrm{s}$. Esto significaría una disponibilidad promedio cercana a la registrada a principios de siglo, de aproximadamente 120 litros por habitante al día, volumen inferior a las recomendaciones de la Organización Mundial de la Salud y muy lejano de las cifras que se manejan al estimar la demanda de agua en la ciudad.

\section{Fugas}

El principal problema que enfrenta el abastecimiento de agua en la Ciudad de México son las fugas, cuyo monto se acerca a $40 \%$ de la oferta, y principalmente son ocasionadas por fracturas y antigüedad de las redes de distribución (Frías, 2000).

Este porcentaje, que resulta excesivo dada la problemática del abasto de agua en la Ciudad de México, no es privativo de ella. En otras ciudades latinoamericanas las fugas se estimaban entre 40 y $70 \%$ en 1986 (Population Information Program, 1999). Incluso en países desarrollados este porcentaje supera $50 \%$, como ocurre en Londres, Los Ángeles y Nueva York. En otras ciudades de México las fugas alcanzan proporciones que varían de 30 a 50 por ciento (GDF, 2000a).

En la parte de la Ciudad de México correspondiente al Distrito Federal se realizó recientemente un estudio de detección de fugas

${ }^{13}$ A fines de los ochenta el consumo per cápita ascendía en promedio en el Distrito Federal a 303 litros, mientras que en el Estado de México, en donde se localizan Chalco y Ecatepec, era de 198 litros. Estos promedios encubren el consumo diferencial, así como el costo diferencial en tre clases sociales. En 1991 un tambo de 200 litros costaba 3000 pesos, lo que representaba $25 \%$ del salario mínimo vigente (García Lascuráin, 1995). 
en el sistema de distribución de agua potable, encontrándose que $22 \%$ de la pérdida deriva de desperfectos en las tomas domiciliarias y $17 \%$ de fallas en la red de distribución. Las causas principales de estas fugas son los hundimientos del terreno y los movimientos sísmi$\cos$. A efecto de solucionar este problema se propuso cambiar las tomas domiciliarias para así recuperar $5 \mathrm{~m}^{3} / \mathrm{s}$ de un total de 23 que se pierden en fugas (GDF, 2000a).

Entre 1998 y 1999 se logró detectar y eliminar multiples fugas en el sistema de distribución y en las tomas domiciliarias, lo que permitió la recuperación de $900 \mathrm{l} / \mathrm{s}$, volumen aún muy modesto respecto al total de la problemática actual (idem).

\section{Tratamiento de aguas}

Ante la evidencia del inadecuado manejo del recurso en la Ciudad de México y su dependencia de las importaciones de otras cuencas, desde 1956 se comenzó a tratar el agua residual, principalmente con el fin de reutilizarla en actividades industriales, en el riego de áreas verdes y deportivas, el llenado de lagos recreativos y el lavado de vehículos.

La primera planta se instaló en Chapultepec y el agua tratada se destina principalmente a llenar los lagos recreativos y al riego de áreas verdes (GDF, 2000b).

En la actualidad se dispone de 27 plantas de tratamiento, $819 \mathrm{~km}$ de red de distribución, 22 plantas de bombeo y 18 tanques de almacenamiento. La capacidad instalada es de $6.3 \mathrm{~m}^{3} / \mathrm{s}$, es decir, alrededor de $10 \%$ del consumo en la ciudad, aunque cabe advertir que las plantas a menudo trabajan a una capacidad muy inferior (idem). La cantidad de agua sometida al proceso es de $4.3 \mathrm{~m}^{3} / \mathrm{s}$, que representa menos de $10 \%$ del flujo de aguas municipales de desecho en época de estiaje, estimado en $44.4 \mathrm{~m}^{3} / \mathrm{s}$. El resto se desaloja hacia el río Tula y es utilizado para regar amplias zonas agrícolas en el estado de Hidalgo, y finalmente desemboca en el Golfo de México.

Con el agua tratada se riegan en el Distrito Federal 6000 ha de tierras agrícolas y 6500 ha de áreas verdes. También son renovadas las aguas de lagos, lagunas y canales (idem).

Mazari-Hiriart et al. (2000) consideran que el reuso y la recarga del acuífero con agua tratada resulta fundamental para enfrentar la demanda futura en la ciudad, y estiman que ello podría contribuir a reducir el déficit en $5 \mathrm{~m}^{3} / \mathrm{s}$ en el mediano y corto plazos. 


\section{Escenarios futuros}

Hasta aquí hemos intentado presentar una visión general de la problemática del manejo del agua en la Ciudad de México, destacando la contradicción entre un ecosistema lacustre con aguas abundantes, la lucha contra el agua y la escasez creciente para abastecer a la población y las actividades económicas de la ciudad.

Es un hecho que la manera en que se ha manejado el agua desde la época colonial no puede reproducirse en el futuro. Existen señales de alarma que hay que atender y que obligan a tomar medidas que garanticen la permanencia de la ciudad.

La perspectiva del futuro puede contribuir al diseño de intervenciones que promuevan un manejo más racional de este recurso vital. En las proyecciones de la demanda futura de agua resulta de suma importancia conocer la dinámica esperada de la población.

El Consejo Nacional de Población calcula que la población de la Ciudad de México pasará de los 18 millones de habitantes con que cuenta en la actualidad, a 19.4 millones en el año 2005 y a 20.5 millones en 2010 (Conapo, 1997).

El efecto que la dinámica de la población tendrá en el abastecimiento de agua en la ciudad provendrá, además del crecimiento de la población a nivel agregado, de la transformación en su estructura por edades y en el tamaño y la composición de los hogares. Conviene mencionar que la mayor proporción de la población se concentra en el grupo de edad de 15 a 40 años con un importante ritmo de crecimiento, y que el tamaño promedio de los hogares tiende a disminuir como resultado de una menor fecundidad, pero también como consecuencia del predominio cada vez más amplio de los hogares nucleares y la creciente importancia de los monoparentales y unipersonales.

Esta situación repercutirá de manera determinante en las necesidades futuras de agua en la ciudad, ya que el grueso de la población está en el grupo de edad responsable de la formación de nuevos hogares y por consiguiente, demandantes de nuevas viviendas con sus respectivos servicios, entre otras muchas cosas.

En los próximos diez años, de continuar las tendencias demográficas conforme se han considerado en las proyecciones, esta situación demandará la cobertura de abastecimiento a más de dos millones de viviendas, pues el total pasará de 3.8 millones en 1995 a 5.7 millones de viviendas en el 2010, con una ocupación promedio que disminuirá en el mismo periodo de 4.4 a 3.6 habitantes (Conapo, 1997). 
¿Qué implicaciones tendría este escenario para la demanda del agua? En primer lugar, el aumento absoluto de 2.7 millones de habitantes entre el año 2000 y el 2010 resultará en una demanda adicional de $3.75 \mathrm{~m}^{3} / \mathrm{s}$, es decir, sumará casi $67 \mathrm{~m}^{3} / \mathrm{s}$ si solamente consideramos un consumo de 120 litros por persona al día, como parece ser el abasto real para fines personales en la actualidad.

Sin embargo, si consideramos la cantidad que se toma en cuenta para la proyección de la demanda por parte de las autoridades encargadas de su abasto (de 351 litros por habitante al día) podemos estimar que en el año 2010 se requerirá un abasto adicional de $11 \mathrm{~m}^{3} / \mathrm{s}$, pasando de uno actual de $63 \mathrm{~m}^{3} / \mathrm{s}$ a uno de 74 metros cúbicos por segundo.

Es decir, la demanda futura de agua basada exclusivamente en las proyecciones de población y de vivienda puede variar entre $67 \mathrm{y}$ $74 \mathrm{~m}^{3} / \mathrm{s}$, para el año 2010. Estas estimaciones, sin embargo, son relativamente conservadoras, ya que no suponen una demanda adicional que podría provenir, por un lado, de menores economías de escala al disminuir el tamaño promedio de los hogares y viviendas, y por el otro, del proceso de desarrollo económico y social, que implica un mayor consumo de agua al modificar los patrones de su uso, con la adopción de hábitos de higiene personal y de las viviendas más intensivos en el consumo de agua. Pero además no consideran el comportamiento futuro de los sectores industrial y de servicios, que seguramente demandarán una mayor dotación del recurso. Mazari-Hiriart et al. (2000) calculan que llegará a $80 \mathrm{~m}^{3} / \mathrm{s}$ para el mismo año.

¿De dónde se podrá obtener este caudal adicional, y a qué costo económico, ambiental, político y social? Se mencionó anteriormente que la explotación del acuífero asciende a alrededor de $40 \%$ de su capacidad de recarga, que la importación de agua de cuencas vecinas impone costos cada vez más elevados, no sólo financieros, sino ecológicos, políticos y sociales, que difícilmente se podrán mantener. Por otro lado, el agua de lluvia suma un caudal promedio de $210 \mathrm{~m}^{3} / \mathrm{s}$ y las aguas superficiales conducen $19 \mathrm{~m}^{3} / \mathrm{s}$ en promedio, lo que representa un potencial nada despreciable para el abasto de agua y para la recarga del acuífero. Sin embargo, su aprovechamiento adecuado se enfrenta a múltiples obstáculos, principalmente en cuanto a su captación, almacenamiento, distribución y posible infiltración (idem). 


\section{Consideraciones finales}

El caso de la Ciudad de México es un ejemplo fascinante de la relación entre el hombre y su medio ambiente; las transformaciones del ecosistema para permitir el asentamiento de su población y para darle sustento han estado regidas a lo largo de la historia, paradójicamente, tanto por el exceso como por la escasez de agua.

Desde los tiempos prehispánicos, una preocupación que dominó la cultura y la economía fue la necesidad de ganarle terreno al sistema de lagos. Se alcanzó este objetivo gracias a la ejecución de importantes obras hidráulicas y a la construcción de chinampas. Pero el crecimiento de la población también hizo necesaria la erección de magnas obras para abastecer de agua potable a la ciudad, trayéndola de manantiales alejados.

Posteriormente a la conquista por la corona española, la solución para ampliar la disponibilidad de suelo urbano e impedir las inundaciones fue sumamente radical: drenar la cuenca de México mediante obras monumentales para su apertura, con impactos ambientales que resultaron en una creciente escasez de agua para el abasto de una población, que comenzó a crecer aceleradamente en el siglo XX.

El nuevo problema, resultante del drenado de la cuenca y del crecimiento de la población, se trató de resolver por medio de la explotación intensiva del acuífero, lo cual provocó serios hundimientos del subsuelo. Estos han ocasionado graves daños al propio acuífero, pero también a la infraestructura hidráulica -tan to de abastecimiento como de drenaje-, por no mencionar los infligidos al resto del equipamiento y a las construcciones urbanas, cuya vulnerabilidad quedó manifiesta durante los sismos de 1985.

En la lucha po aprovechar el agua, las soluciones técnicas que se han empleado han originado efectos adversos que reclaman nuevas soluciones técnicas, cada vez más costosas e insustentables desde el punto de vista ecológico y social.

No obstante, el ecosistema lacustre reclama frecuentemente su origen natural, si bien las autoridades gubernamentales consideran que las inundaciones de la ciudad son menos frecuentes y de menor intensidad (GDF, 2000a).

La explotación del acuífero y la importación de agua de cuencas lejanas son una muestra clara de un mal manejo de un recurso esencial para la reproducción de la vida humana y de los ecosistemas. El abasto natural que ofrecían los lagos originales, la lluvia, los ríos y los 
manantiales, ahora extintos, pudieron garantizar la satisfacción de una parte importante de las necesidades.

Las perspectivas de la demanda futura no son muy optimistas, dado que el incremento de la población y el mayor número de viviendas, reclamarán un caudal cada vez más grande.

A efecto de garantizar la satisfacción de las necesidades de las generaciones futuras, será necesario imaginar nuevas formas de relación con el agua. La manera en que se ha abastecido a la población de la ciudad ha demostrado ser insustentable, pues agotó los depositos superficiales, otrora principal fuente de abastecimiento.

El inadecuado aprovechamiento del recurso ocasionado por la elevada cantidad de fugas, su desigual distribución entre los distintos grupos sociales, el subsidio exagerado en su cobro, así como la combinación de aguas limpias provenientes de lluvia y cuerpos superficiales de agua, junto con las aguas servidas municipales, llaman la atención acerca de la urgente necesidad de cambiar la modalidad del manejo del agua. Ello a efecto de aprovechar sustentablemente la que aún recibe la cuenca de manera natural, en beneficio no sólo de las generaciones futuras de seres humanos sino de otras especies que han habitado la cuenca desde tiempos ancestrales y que han sucumbido a la extinción.

La Ciudad de México presenta un ejemplo claro de la forma en que diversos procesos inciden en un mal manejo de los recursos naturales por parte de la sociedad humana.

La historia de la ocupación del valle, la apertura de la cuenca, ei secado de los lagos, la sobreexplotación del acuífero, el entubamiento de los ríos y su drenaje junto con las aguas servidas municipales, así como la dependencia de cuencas lejanas para garantizar el abastecimiento de las generaciones presentes, demuestran la capacidad de la sociedad para ampliar los límites naturales del ecosistema con el afán de sostener a una creciente población. Ello será factible siempre y cuando se disponga de los recursos económicos, tecnológicos, políticos y culturales que faciliten la importación de recursos provenientes de otros ecosistemas.

En la Ciudad de México ha sido fundamental el acceso a la tecnología que desde tiempos prehispánicos permitió ganarle terreno a los lagos, más tarde sentó las bases para desalojar el agua del valle por las aperturas artificiales de la cuenca, y posteriormente dio lugar a la explotación del agua subterránea y la conducción del líquido desde otras cuencas. 
Pero más importante que la tecnología y los recursos necesarios para financiar las obras correspondientes, las dimensiones política y cultural han influido de manera determinante en la relación de la sociedad con uno de sus recursos naturales más preciados.

El predominio del imperio azteca, más tarde el de la capital de Nueva España y en la época independiente de la Ciudad de México, ha legitimado la explotación de los recursos internos y externos de la cuenca de México en beneficio de un proyecto concentrador de población, recursos económicos y poder político, que ha demostrado ser no sustentable desde el punto de vista ecológico y social.

La Ciudad de México requiere desplegar todas sus capacidades técnicas, económicas, sociales, culturales y políticas y lograr el concurso de todos los grupos sociales, a efecto de garantizar un abasto permanente de agua a la creciente población y a sus actividades productivas, sin imponer una carga adicional al deteriorado ecosistema que nos hemos empeñado en destruir a lo largo de la historia.

\section{Bibliografía}

Academia de la Investigación Científica, Academia Nacional de Ingeniería, Academia Nacional de Medicina y National Academy of Sciences (coords.) (1995), El agua y la Ciudad de México. Abastecimiento y drenaje, calidad, salud pública, uso eficiente, marco jurídico e institucional, México.

Arnold, David (2000), La naturaleza como problema histórico. El medio, la cultura y la expansión de Europa, México, Fondo de Cultura Económica.

Buenrostro, César (2000), "Agua, factor determinante del desarrollo de la Ciudad", ponencia presentada en el Foro Estrategias Ambientales para la Ciudad de México en su Perspectiva Megalopolitana hacia el siglo XXI, Museo de la Ciudad de México, junio 5 (mimeo.).

Chávez, Mónica (1994), "La ciudad de agua: los aztecas", El agua en el México antiguo, México, pp. 59-79 (Salvat Ciencia y Cultura).

CNA (Comisión Nacional del Agua) (1994), El agua y sus senderos. Ríos, lagos y cascadas de México, México, Comisión Nacional del Agua.

(1999), "Distribuciones promedio de agua para usos urbano e industrial para la ZMVM por fuente de suministro caudal medio", Gerencia Regional de Aguas del Valle de México (mimeo.).

—__ y Semarnap (Secretaría de Medio Ambiente, Recursos Naturales y Pesca) (1997), Sistema Cutzamala. Agua para millones de mexicanos, México, Comisión Nacional del Agua. 
Conapo (Consejo Nacional del Población) (1997), Escenarios demográficos y urbanos de la Zona Metropolitana de la Ciudad de México, 1990-2010. Sintesis, México, Consejo Nacional de Población.

DGCOH (Dirección General de Construcción y Operación Hidráulica) (2000a), "Cronología agua potable. Época virreinal", en http://www.dgcoh.gob. $\mathrm{mx}$ /virreinalap.html

(2000b), "Cronología agua potable", en http://www.dgcoh.gob.mx/ historia.html

- (2000c), "Cronología agua potable. Epoca independiente", en http: //www.dgcoh.gob.mxindependienteap.html

Encinas, Alejandro (1999), "El GDF ha logrado revertir la pérdida de reservas ecológicas", entrevista de Bertha Teresa Ramírez, La Jornada, 6 de septiembre, México, p. 54.

Ezcurra, Exequiel (1990), De las chinampas a la megalópolis. El medio ambiente en la cuenca de México, México, Fondo de Cultura Económica (La ciencia desde México, 91 ).

— y Marisa Mazari-Hiriart (1996), "Are Megacities Viable? A Cautionary Tale from Mexico City", Entironment, vol. 38, núm. 1, pp. 6-35.

Frías, Manuel (2000), "Abastecimiento de agua para la Cuenca del Valle de México", en Marcos Mazari (comp.) Dualidad población-agua. Inicio del tercer milenio, México, El Colegio Nacional, pp. 41-86.

Gamboa de Buen, Jorge (1994), Ciudad de México, una visión, México, Fondo de Cultura Económica (Una Visión de la Modernización de México).

García-Calderón, José Luis y Guadalupe de la Lanza (1995), "La cuenca de México", en Guadalupe de la Lanza y José Luis García Calderón (comps.) Lagos y presas de México, México, Centro de Ecología y Desarrollo.

García Lascuráin, María (1995), Agua y calidad de vida en Chaleo y Ecatepec, México, Centro de Ecología y Desarrollo.

GDF (Gobierno del Distrito Federal) (2000a), "Sistema de drenaje", en http://www.df.gob.mx/secretarias/obras/cuaderno/drenaje.html

- - (2000b), "Aguas residuales", en http://www.df.gob.mx/ secretarias/obras/cuaderno/aguaresidual.html

Guerrero, Manuel (1998), El agua, México, Fondo de Cultura Económica (La Ciencia para Todos, 102).

Herrera, Ismael (ed.) (1989), El sistema acuífero de la cuenca de México, volumen especial de Geofisica Internacional, vol. 28, núm. 2.

— R. Medina, J. Carrillo y E. Vázquez (1994), "Diagnóstico del estado presente de las aguas subterráneas de la Ciudad de México y determinación de sus condiciones futuras", DDF-DGCOH/Instituto de Geología, UNAM.

INEGI (Instituto Nacional de Estadística, Geografía e Informática) (2000a), XII Censo nacional de población y vivienda 2000. Resultados preliminares. Aguascalientes, México.

- (2000b), XII Censo nacional de población y vivienda 2000. Tabulados de la muestra censal. Cuestionario ampliado, Aguascalientes, México. 
Izazola, Haydea y Catherine Marquette (1999), "Emigración de la Ciudad de México, ¿estrategia de sobrevivencia frente al deterioro ambiental?", en Raúl Benítez y René Jiménez (coords.), Hacia la demografía del siglo XXI, México, IISUNAM/Somede, pp. 113-135.

Legorreta, Jorge (1997), "Agua de lluvia, la llave del futuro en el Valle de México", La Jornada Ecológica, año 5, núm. 58, 28 de julio, México.

López Rosado, D. (1988), El abasto de productos alimenticios en la Ciudad de México, México, Fondo de Cultura Económica.

Mazari, Marcos (1997), "El reuso de agua residual en el salvamento de la subcuenca Zumpango", en Marcos Mazarí (coord.), Hacia el tercer milenio (un complemento), México, El Colegio Nacional, pp. 9-15.

y Jesús Alberro (1990), "Hundimiento de la Ciudad de México", en Jesús Kumate y Marcos Mazari (coords.) Problemas de la Cuenca de México, México, El Colegio Nacional, pp. 83-114.

Mazari-Hiriart, Marisa y Mauricio Bellón (1995), "Sustentabilidad del desarrollo urbano: Agua", en Adrián Aguilar, Luis Javier Castro y Eduardo Juárez (coords.), El desarrollo urbano a fines del siglo XX, Monterrey, Instituto de Estudios Urbanos de Nuevo León/Sociedad Mexicana de Demografía, pp. 165-178.

-, Luis Antonio Bojórquez, Adalberto Noyola y Salomón Díaz (2000), "Recarga, calidad y uso del agua en la Zona Metropolitana de la Ciudad de México", en Marcos Mazari (comp.), Dualidad población-agua. Inicio del tercer milenio, México, El Colegio Nacional, pp. 137-165.

Murillo, R. (1990), "Sobreexplotación del acuífero de la cuenca del Valle de México: efectos y alternativas", en El subsuelo de la cuenca del Valle de México y su relación con la ingeniería de cimentaciones a cinco años del sismo, México, Sociedad Mexicana de Mecánica de Suelos, pp. 109-119.

Musset, Alain (1996), "De Tláloc a Hipócrates. El agua y la organización del espacio en la Cuenca de México (siglos XVI-XVIII)", en Alejandro Tortolero Villaseñor (coord.), Tierra, agua y bosques: Historia y medio ambiente en el México central, Centre Francais d'Etudes Mexicaines et Centroaméricaines/Instituto de Investigaciones Dr. José María Luis Mora/Potrerillos Editores/Universidad de Guadalajara.

Niederberger, C. (1987), "De la prehistoria a los primeros asentamientos humanos en la Cuenca de México", en Gustavo Garza (comp.), Atlas de la Ciudad de México, México, El Colegio de México/Departamento del Distrito Federal, pp. 40-42.

Partida, Virgilio (1994), "La Ciudad de México. Nuevo derrotero en su ritmo de crecimiento", Demos. Carta Demográfica sobre México, 1994, núm. 7, pp. $13-14$.

Population Information Program (1999), "Soluciones para un mundo con escasez de agua", Population Reports, serie M, núm. 14, Baltimore, The Johns Hopkins School of Public Health.

Ramírez, Carlos (1990), "El agua en la Cuenca de México", en Jesús Kumate y Marcos Mazari (coords.), Problemas de la Cuenca de México, México, El Co- 
legio Nacional, pp. 61-80.

Serra Puche, Mari Carmen (1990), "El pasado ¿una forma de acercarnos al futuro? 25 mil años de asentamientos en la Cuenca de México", en Jesús Kumate y Marcos Mazari (coords.), Problemas de la Cuenca de México, México, El Colegio Nacional, pp. 3-28.

Sanders, William T., Jeffrey R. Parsons y Robert S. Stanley (1976), The Basin of Mexico: Ecological Processes in the Evolution of a Civilization, Nueva York, Academic Press. 